\title{
CENÁRIOS EDUCACIONAIS NA CONTEMPORANEIDADE: REFLEXÕES A RESPEITO DAS DIFERENÇAS E DAS PERFORMANCES
}

\author{
ESCENARIOS EDUCATIVOS EN LA CONTEMPORANEIDAD: REFLEXIONES \\ ACERCA DE LAS DIFERENCIAS Y DE LAS PERFORMANCES
}

\section{EDUCATIONAL SCENARIOS IN THE CONTEMPORARY WORLD: REFLECTIONS ON DIFFERENCES AND PERFORMANCES}

\author{
Carlos Roberto SABBI ${ }^{1}$ \\ Geraldo Antônio da ROSA ${ }^{2}$ \\ Agustín de la HERRÁN GASCÓN ${ }^{3}$
}

RESUMO: O presente artigo tem como objetivo identificar os elementos mais importantes que, atualmente, geram desigualdades na educação, a partir de perspectivas local e global, entendendo, assim, sua realidade sob uma visão ampla. Para tanto, recorreu-se à hermenêutica reconstrutiva, por entendê-la como uma metodologia adequada para abordar a questão. A busca e objetivação desses elementos são a consequência inevitável para propiciar a compreensão do atual cenário. Nesse sentido, a pesquisa é apoiada por uma avaliação crítica dos relatórios do PISA, entendida como uma fonte de análise comparativa de relevância extraordinária no momento. Como resultado e dentro de um contexto internacional e localmente construído, verificam-se as diferenças de desempenho em educação no Brasil, principalmente quando comparadas com as de países de melhores resultados. Embora, historicamente, a Finlândia e a Coreia do Sul tenham dados melhores nos relatórios do PISA, mesmo com diferentes estratégias e políticas, conclui-se que, acima de qualquer tipo de ação, há o foco, como é entendido no campo das Ciências da Administração.

PALAVRAS-CHAVE: Ambiente educacional. Análise de fatores. Contexto de aprendizagem. Desenvolvimento da educação. Desigualdade cultural.

RESUMEN: El objetivo del texto es identificar los elementos más importantes que, en la actualidad, generan desigualdades en la educación, desde una perspectiva global. Con ello se pretende comprender su realidad con una perespectiva macro. Para responder al objetivo se ha recurrido a la hermenéutica reconstructiva, por entenderla como una metodología

${ }^{1}$ Universidade de Caxias do Sul (UCS), Caxias do Sul - RS - Brasil. Doutorando em Educação pela Universidade de Caxias do Sul em cotutela com a Universidade Autônoma de Madrid. ORCID: http://orcid.org/0000-0002-0319-6024. E-mail: crsabbi@gmail.com

${ }^{2}$ Universidade de Caxias do Sul (UCS), Caxias do Sul - RS - Brasil. Docente/pesquisador no programa de pósgraduação em educação. Doutor em teologia. líder do Grupo de Estudos e Pesquisa em Educação Básica (GEPEB), pesquisador do Grupo de Pesquisa Formação Cultural, Hermenêutica e Educação (GPFORMA). Coordena o Grupo de Pesquisa Formação Cultural, Hermenêutica e Educação. ORCID: http://orcid.org/00000002-1193-7910. E-mail: geraldorosa06@gmail.com

${ }^{3}$ Universidade Autônoma de Madri (UAM), Madri - Espanha. Doutor e Professor titular da Universidade de Didática e Organização Escolar. Dois sexenios de investigação CNEAI. Foi coordenador do Programa de Doutorado "Inovação e Formação de Professores", coordenador do Programa de Pós-graduação em Educação da UAM. ORCID: http://orcid.org/0000-0001-9156-6971. E-mail: agustin.delaherran@uam.es 
adecuada para tratar el asunto. La búsqueda y objetivación de esos elementos son la consecuencia inevitable para propiciar esa comprensión. La investigación se apoya en una valoración crítica de los informes PISA, entendidos como una fuente de evaluación comparada de extraordinaria relevancia en la actualidad. Como resultado y dentro de un contexto internacional y localmente construido, se constatan las diferencias de desempeño en la educación en Brasil, especialmente si se compara con las de países con mejores resultados. Aunque históricamente, Finlandia y Corea del Sur tengan mejores datos en los informes PISA, incluso con diferentes estrategias y políticas, se concluye que, por encima de cualquier tipo de acción, está el 'foco', tal y como se entiende en el campo de las Ciencias de la Administración.

PALABRAS CLAVE: Ambiente educacional. Análisis de factores. Contexto de aprendizaje. Desarrollo de la educación. Desigualdad cultural.

ABSTRACT: The purpose of the text is to identify which are the elements these days that generate inequalities in education, from a local and global perspective. This aims to understand its reality with a macro perspective. In order to answer the objective, it was used the reconstructive hermeneutics, which is seen as a suitable methodology to address the question. The search for these elements is the inevitable consequence of this understanding. The research is supported by a critical evaluation of the PISA reports, understood as a comparative source of extraordinary relevance now. As a result, within an international and locally constructed context, the differences in performance in education in Brazil are significant, especially when compared with those countries with better results. Although historically, Finland and South Korea have better data in the PISA reports, even with different strategies and policies, it is concluded that, above any kind of action, there is the focus, as it is understood in the field of the Administrative Sciences.

KEYWORDS: Cultural inequality. Development of education. Educational environment. Factor analysis. Learning context.

\section{Introdução}

O cuidar de si e o cuidar de todos sempre será objeto-foco da educação, quer no ambiente familiar, quer no escolar, quer no acadêmico, no sentido de fornecer informações sistematizadas e incentivar sua reflexão para que se possa construir conhecimento. Os pais ou os familiares responsáveis pelos menores são os primeiros e fundamentais pedagogos, pois, de certa forma, são os que mais podem influenciar na formação do caráter e inspirar os primeiros traços da personalidade. Esses primeiros pedagogos, além de transmitirem os elementos civilizatórios, são os que, possivelmente, incentivarão a construção das noções de importância dos processos de educação na criança, que se caracterizarão pelo respeito aos educadores e à escola, além do foco que cada um dará ao seu processo de aprendizado.

A família não é a única instituição de socialização que afeta os percursos das gerações 
em formação. Há fatores endógenos e exógenos que concorrem para as diferentes configurações sociais que compõem a sociedade. Muitas vezes, a família e a escola são reféns de um sistema excludente e competitivo que acompanha as relações sociais. Essas são variáveis externas ao domínio da família e da educação, fato que coloca um extremo grau de dificuldade na formação escolar em especial, mas que concorre com os processos educativos em todas suas fases do desenvolvimento.

Com base nesses fatores, os quais por si só já, de certa forma, configuram um grau considerável de complexidade, é impossível se falar em Educação sem considerar os condicionamentos do sujeito, os quais se referem a todo um conjunto de influências e manipulações, consciente ou não. Sendo assim, se não for a Educação que tratará dos descondicionamentos, quem os faria? De fato, esse assunto é extremamente complexo desde seu ponto de vista filosófico até às questões práticas do dia a dia, no entanto parece muito oportuno as sociedades, por meio da Educação, abordar e atacar diferentes processos de condicionamento cognitivo.

O valor atribuído à Educação institucionalizada ou formal no Brasil não faz por merecer a sua importância. Com algumas variações, o contexto mundial não é muito diferente, mesmo havendo exemplos extraordinários de transformação de nações inteiras, provocadas pelo forte investimento na Educação.

Desde sua criação, a Declaração Universal dos Direitos Humanos (DUDH) inspirou a Constituição de muitos Estados e democracias recentes, sendo traduzida em mais de 360 idiomas. A DUDH, no site da United Nations (United Nations Human Rights, 2015), apresenta a palavra education repetidamente oito vezes, sem mencionar uma única vez a palavra instruction. Essa Declaração, traduzida para o português brasileiro, disponível em uma página do Ministério da Educação (BRASIL, 2004), traz apenas uma vez a palavra educação e oito vezes a palavra instrução. Não é necessário discorrer sobre o significado e as enormes diferenças entre esses dois conceitos. Entretanto, o simbolismo desse equívoco abismal exatamente com o termo educação, em um documento com tamanha expressividade, se não a maior, reflete, metaforicamente, a importância que é dada à educação no Brasil, ou de certa forma, poder-se-ia destacar alguns equívocos em termos de tradução no que se refere às categorias mencionadas.

Antes de passar para o próximo tópico, é preciso deixar registrado um comentário sobre uma possível revisão de literatura sobre o tema que se está enfocando. O fato é que uma literatura aproximada ao que aqui se está abordando, possivelmente por se tratar de aspectos 
contemporâneos, praticamente não existe, visto que não se localizou artigos ou outras obras tratando sob o prisma que este artigo adotou.

Outrossim, a própria análise dos dados do exame do PISA foi algo elaborado inteiramente sob os relatórios de todas as suas edições e, por mais incrível que possa parecer, não se encontrou outros tipos de análises. Se existem, mesmo por parte dos organismos do governo brasileiro, não foram divulgadas sob esse aspecto de análise gerencial. Portanto, a revisão da literatura foi prejudicada, motivo de sua ausência neste trabalho.

\section{Metodologia}

Utilizou-se a metodologia da hermenêutica reconstrutiva por ser uma das formas mais adequadas de tratar do assunto, que busca levantar cenários da atualidade dentro do contexto da Educação. O objetivo é qualificar o processo, de uma forma geral, enquanto horizonte teórico, fazendo da hermenêutica reconstrutiva um método empírico de investigação. A propósito, sobre metodologia, Trevisan e Devechi citam que

se, em Kant, os conhecimentos deviam passar pelo crivo da crítica da razão pura, para Habermas trata-se de buscar sua validação pelo exercício da crítica da razão prática, isto é, de uma razão comprometida com o exercício hermenêutico do diálogo, não como opção metodológica exclusivamente, ou seja, como mais um método posto à disposição dos educadores, mas como polo do entendimento possível (2011, p. 423).

É preciso observar, também, que uma interpelação sob a ótica hermenêutica dentro do contexto da educação sempre identificará a produtividade da experiência do estranhamento e até de um certo desconforto, tendo em vista o procedimento natural de romper com o status $q u o$, e sendo isso um imperativo da metodologia e do próprio processo para o entendimento. De fato, faz parte de todo procedimento de mudanças, em que se rompe paradigmas, deslocando o sujeito de sua zona de conforto. Parece que a educação, dentro de seus elementos primordiais, não surge por abstrações, e a hermenêutica-reconstrutiva colabora com horizontes de desconstruir e reconstruir, enquanto metodologia de pesquisa, ajudando a arquitetar processos educativos pelo empirismo e com um nível considerável de aceitação dos aspectos imprevisíveis, fato que tende a ser importante para agregar novos aspectos dos saberes.

Por outro lado, talvez neste ponto seja importante destacar e valorizar a importância da pluralidade nos seus mais diversos aspectos dentro da educação, como estratégia de abarcar 
todo tipo de conhecimento, de modo que isso em forma de informações se produzam novos tipos de conhecimentos.

\section{A educação e os condicionamentos como entraves na plenificação do ser}

Tudo o que a vida oferece ao sujeito, desde seu nascimento até seu último dia de vida, de certa forma, são condicionantes, pois lhe é dito o que é certo ou errado, o tipo de vestimenta que deve usar de acordo com a moda do momento, o que é bom e o que é ruim, etc. Essa própria retórica para explicar o que são os condicionantes, se for uma tentativa de se impor ao invés de a colocar como uma mera possibilidade da sua definição, poder-se-ia dizer que no mínimo se trata de um ensaio para se tornar um condicionante. E isso acontece em todos os campos da vida, quer seja no mercado, na política, na religião, quer em todos os demais.

A abordagem sob esse aspecto do condicionamento é recente na história ocidental e isso pode ser constatado pela sua, praticamente, ausência dos dicionários de filosofia. Entretanto, ela surge como uma importante interpelação filosófica, ao ponto de se tornar possível o questionamento de até que ponto existe um "eu".

A educação sempre deverá abarcar todos os principais aspectos que envolvem a vida, sob os mais diferentes pontos de vista ou de ideologias. Se houver a predominância de alguns pontos de vista ou de ideologias, em detrimento ao conjunto de conhecimentos já produzidos pela humanidade, estar-se-á caminhando rumo ao doutrinamento, que nada mais é do que a própria antítese da educação.

Abbagnano define educação:

A Educação é definida como formação do homem, amadurecimento do indivíduo, consecução da sua/forma completa ou perfeita, etc.: portanto, como passagem gradual - semelhante à de uma planta, mas livre — da potência ao ato dessa forma realizada. Esses conceitos repetem-se com tal uniformidade na tradição pedagógica que não chegam a constituir novidade do ponto de vista filosófico. Segundo esse ponto de vista, a Educação é cultura, no segundo dos dois significados fundamentais deste termo; os problemas gerais correspondentes podem ser estudados nesse verbete (ABBAGNANO, 2007, p. 306).

A partir dessa conceituação, especialmente com o indivíduo como fim da educação, torna-se impossível admitir que se omita pontos de vista e muito menos conhecimentos distintos em um processo formativo, sob a pena eminente da sua caracterização como doutrinamento. A propósito, sobre doutrinamento (BUNGE, 2002, p. 102-103) diz se tratar 
de "Coleção de proposições ensinadas como sendo verdadeiras por algumas escolas. As doutrinas são menos bem organizadas do que as teorias, e não dispõem necessariamente de suporte empírico. Podem ser seculares ou religiosas". Como se constata em sua definição há uma significativa diferença entre Educação e Doutrinamento e, enquanto a primeira tende a oferecer uma ampla formação, a segunda se prende somente a alguns aspectos. Nesse sentido, torna-se claro o risco pela tendência previamente alinhada do doutrinamento levar ao que se pode entender como viés contrário de uma ampla formação, que somente pela Educação é possível se aproximar. Portanto, além do condicionamento como embaraço natural da Educação, tem-se os ricos de se ter processos formativos incompletos ou com viés de doutrina.

A Pedagogia radical e inclusiva é um extenso e profundo trabalho desenvolvido por Herrán Gascón, há 30 anos aproximadamente, identificando temas radicais por meio de critérios rígidos e claros que detectam hiatos importantes nos processos educativos, dentre os quais se destaca o ensino pré-natal, a criança como pedagoga e o estudo sobre a morte, dentre vários outros temas. Esse trabalho identifica os temas abordados pela Educação tradicional como demandados pela sociedade e os temas radicais como não demandados, mas necessários para a formação cidadã. Herrán Gascón propõe a criação de um currículo para a Educação em três dimensões, baseado na consciência, formado pelos temas transversais, radicais e as áreas curriculares ou materiais.

Herrán Gascón (2014) diz que é próprio do ser humano fazer interpretação das coisas que ele percebe. Porém, obviamente há uma enorme diferença entre interpretar e compreender. Nesses processos, em ambos os casos, há vários aspectos envolvidos a serem considerados. Os fundamentos da pedagogia radical de Herrán Gascón são compostos pela investigação, inovação e autoformação para se chegar à evolução da consciência. Os constructos radicais e inclusivos para a formação são compostos da consciência, maturidade pessoal, evolução da humanidade e egocentrismo para se atingir o autoconhecimento.

Dessa forma, ela busca alternativas para que os processos formativos possam desenvolver um descondicionamento à medida que se aprimora dez competências: imaginação; criatividade; experimentação; meditação; raciocínio lógico; criticidade; espírito investigativo; virtude; espiritualidade e o agir comunicativo.

Com esses elementos sistematizados nos processos educacionais e assimilados pelo sujeito, ter-se-ia uma aproximação de uma condição da qual poder-se-ia dizer existir um desenvolvimento humano. Além disso, a possibilidade de uma diminuição das desigualdades sob os mais diversos aspectos, entre as pessoas, seria uma realidade, fato que é um dos 
problemas históricos da humanidade e, muito especialmente, no Brasil, país que possui um dos maiores índices de desigualdades do planeta, medido sob as mais diversas fórmulas, em que o coeficiente de Gini ${ }^{4}$ é o mais famoso.

\section{A educação do Brasil na contemporaneidade}

É notória a importância de se buscar, por meio de pesquisas, desenvolver processos avaliativos em qualquer atividade profissional da contemporaneidade, dentro de uma perspectiva da administração científica. Na Educação, obviamente isso não é diferente, muito embora haveria muitos outros aspectos a serem discutidos sob esse enfoque de um gerenciamento profissional, nessa área propriamente dita. Contudo, no intuito de dar objetividade à proposta de se debater os cenários educacionais na contemporaneidade, com suas reflexões a respeito das diferenças e das performances, precisa-se delimitar o tema, motivo pelo qual se concentrarão as análises a partir de algumas das avaliações existentes.

Um dos fatos mais significativos da realidade atual da educação brasileira diz respeito à implantação da "progressão continuada". Este horizonte tem como suporte a Lei de Diretrizes e Bases da Educação Nacional, quando começou a ser implementada pelas escolas. $\mathrm{Na}$ avaliação dos estudantes em Matemática e Ciências, seis dos dez países primeiros colocados no exame do PISA $^{5}$ adotam algum sistema de progressão continuada; no quesito Leitura, o número sobe para oito. Entre eles estão: China, Finlândia, Irlanda, Holanda, Canadá, Coreia do Sul, Japão e Cingapura.

Apesar de a progressão continuada ser sinônimo de sucesso em muitos países, no Brasil, ela ainda enfrenta resistência. O fato é que, de certa forma, nesses países o sistema funciona. Lá, as escolas optam por um sistema de apoio intenso ao aluno, fato que está sendo impossível aplicar no Brasil, aparentemente, pela falta de estrutura e a quantidade e qualidade dos recursos pedagógicos disponíveis. Nesses países, o acompanhamento do aluno se dá dentro e fora da sala de aula, e a maior parte deles possui condições socioeconômicas superiores às do Brasil. A leitura que se faz é que a progressão continuada repensa as posturas

${ }^{4}$ O Coeficiente de Gini é uma medida de desigualdade desenvolvida pelo estatístico italiano Corrado Gini, e que pode ser utilizado para qualquer arranjo. É considerada a fórmula mais popular de medir a desigualdade de distribuição de renda. Nota do autor.

5 O Programme for International Student Assessment (Pisa) - Programa Internacional de Avaliação de Estudantes - é uma iniciativa de avaliação comparada, aplicada de forma amostral a estudantes matriculados a partir do $7^{\circ}$ ano do ensino fundamental na faixa etária dos 15 anos, idade em que se pressupõe o término da escolaridade básica obrigatória na maioria dos países. O Pisa é coordenado pela Organização para Cooperação e Desenvolvimento Econômico (OCDE), havendo uma coordenação nacional em cada país participante. No Brasil, a coordenação do Pisa é responsabilidade do Inep. Disponível em: http://portal.inep.gov.br/pisa. Acesso em: 19 nov. 2018 
e percepções em face da educação, articulando-se ao fazer pedagógico e importando amplo desafio para todos os profissionais da educação.

No Brasil, essa política educacional de progressão enfrenta sérias críticas por parte da sociedade. Os professores, em geral, por sua vez, creem e de certa forma ainda reproduzem a cultura da reprovação, sendo este incentivo por um lado, e por outro, um meio biopolítico de controle aos estudantes. Outra crítica recorrente é a de que o fenômeno do "copismo", relacionado ao analfabetismo funcional, vem aumentando devido à progressão continuada.

Outro elemento significativo da educação no país foi a criação do Índice de Desenvolvimento da Educação Básica (IDEB) pelo Instituto Nacional de Estudos e Pesquisas Educacionais Anísio Teixeira (Inep) em 2007. O site do INEP apresenta a definição de IDEB:

O Índice de Desenvolvimento da Educação Básica (Ideb) foi criado em 2007 e reúne, em um só indicador, os resultados de dois conceitos igualmente importantes para a qualidade da educação: o fluxo escolar e as médias de desempenho nas avaliações. Ele é calculado a partir dos dados sobre aprovação escolar, obtidos no Censo Escolar, e das médias de desempenho nas avaliações do Inep, o Sistema de Avaliação da Educação Básica (Saeb) para as unidades da federação e para o país, e a Prova Brasil - para os municípios (BRASIL, 2015).

Conceitualmente, o Ideb foi criado para ser condutor de política pública pela melhoria da qualidade da educação, tanto no âmbito nacional como no dos estados, dos municípios e das escolas. As metas são o caminho delineado de melhora individual dos índices, de forma que o Brasil alcance o nível educacional da média dos países da Organização para Cooperação e Desenvolvimento Econômico (OCDE). Estatisticamente, isso significa evoluir da média nacional de 3,8, apontada em 2005, para um Ideb igual a 6,0, na primeira fase do Ensino Fundamental.

As metas do Ideb são diferenciadas para cada rede e escola, assim como apresentadas bienalmente desde 2007, com previsão para seguir continuamente até 2021. Estados, municípios e escolas deverão melhorar seus índices e contribuir, conjuntamente, para que o Brasil chegue à meta de 6,0 em 2022. No caso das redes e escolas com maior dificuldade, é previsto um esforço mais concentrado para que melhorem rapidamente, diminuindo, assim, a desigualdade entre as esferas. Considera-se que o processo de avaliação numa visão geral é importante. Entretanto, não cumpre seu objetivo no momento em que deixa de ser indicadores para tomada de decisões a respeito do processo, sendo utilizado como elemento para o ranqueamento e marketing. 
Outro elemento significativo na contemporaneidade da educação, no Brasil, é o Exame Nacional do Ensino Médio (ENEM). Criado em 1998 com o intuito de medir a atuação do estudante ao fim da Educação Básica, procura colaborar para a melhoria da qualidade desse plano de escolaridade. A partir de 2009, passou a ser utilizado, também, como processo seletivo para ingresso no Ensino Superior.

O Enem busca contribuir para a democratização das oportunidades de acesso às vagas oferecidas por Instituições Federais de Ensino Superior (Ifess), para a mobilidade acadêmica e para induzir à reestruturação dos currículos de Ensino Médio, tendo como um de seus princípios básicos o respeito à autonomia das universidades. Os resultados do Enem podem ser utilizados para acesso ao Ensino Superior, que pode ocorrer como fase única de seleção ou combinado com processos seletivos próprios. Além disso, também é utilizado para o acesso a programas oferecidos pelo governo federal, como o Programa Universidade para Todos (ProUni).

A melhor análise parte dos números, seja pela observância quantitativa, seja pela qualitativa, para, depois, serem agregadas todas às demais variáveis possíveis, desde que pontualmente observáveis e de alguma forma mensuráveis. Dentro dessa premissa, apuraramse os dados existentes de todos os resultados do Programa Internacional de Avaliação de Estudantes (Pisa) que foram agrupados pelos destaques que importam à análise do desempenho dos alunos brasileiros em comparação aos demais países, conforme pode ser visto no Quadro 1.

Quadro 1 - Desempenho consolidado da média do Pisa

\begin{tabular}{|l|c|c|c|c|c|}
\hline \multirow{2}{*}{\multicolumn{1}{|c|}{ PAIÍS }} & \multicolumn{5}{c|}{ MÉDIA DO PISA } \\
\cline { 2 - 6 } & $\mathbf{2 0 0 0}$ & $\mathbf{2 0 0 3}$ & $\mathbf{2 0 0 6}$ & $\mathbf{2 0 0 9}$ & $\mathbf{2 0 1 2}$ \\
\hline BRASIL & 368 & 383 & 384 & 401 & 402 \\
\hline FINLÂNDIA & 540 & 545 & 553 & 543 & 529 \\
\hline COREIA & 541 & 538 & 542 & 541 & 543 \\
\hline GERAL & 473 & 485 & 467 & 469 & 476 \\
\hline No PAÍSES & 43 & 41 & 56 & 66 & 66 \\
\hline POSIÇÃO BRASIL & $42 / 43$ & $39 / 41$ & $51 / 56$ & $55 / 66$ & $58 / 66$ \\
\hline $\begin{array}{l}\text { MELHOR } \\
\text { POSIÇÃO }\end{array}$ & 543 & 545 & 553 & 577 & 588 \\
\hline PIOR POSIÇÃO & 317 & 373 & 306 & 325 & 375 \\
\hline $\begin{array}{l}\text { \% BRASIL X } \\
\text { MELHOR }\end{array}$ & 67,77 & 70,28 & 69,44 & 69,5 & 68,37 \\
\hline \% BRASIL x PIOR & 116,1 & 102,7 & 125,5 & 123,4 & 107,2 \\
\hline $\begin{array}{l}\text { \% BRASIL X } \\
\text { GERAL }\end{array}$ & 77,8 & 78,97 & 82,23 & 85,5 & 84,45 \\
\hline
\end{tabular}

Fonte: elaborado pelo autor (2018), com base nos dados do PISA (OCDE, 2016). 
Primeiro, é possível constatar que o Brasil cresceu 34 pontos desde a primeira até a última edição do Pisa, ocorrendo crescimento, basicamente, em dois momentos: em 2003, cresceu 15 pontos; e, em 2009, 17 pontos. A colocação do Brasil foi de 42a entre 43 países em 2000; passando a $39^{\mathrm{a}}$ entre 41 países em 2003; a $51^{\text {a }}$ entre 56 países em 2006; a $55^{\text {a }}$ entre 66 países em 2009; e a $58^{\text {a }}$ entre 66 países em 2012. Salienta-se que foram considerados apenas os países que tiveram todas as avaliações realizadas em cada ano de apuração. Assim, aqueles que tiveram apurações parciais, ou não tiveram nenhuma avaliação, não foram considerados sob qualquer hipótese.

O desempenho médio total dos países participantes se manteve praticamente inalterado nesses 12 anos (2000-2012), enquanto a pontuação média do país que obteve a primeira colocação subiu 45 pontos, bem como a média do país que ficou na última colocação subiu 58 pontos. Como visto, o Brasil também subiu nesse mesmo período 34 pontos.

O desempenho médio total do Brasil em relação ao desempenho médio do país que ficou em primeiro lugar, nesses 12 anos, praticamente se manteve inalterado, apresentando 68,37\% em 2012, enquanto em relação ao último colocado, no mesmo ano, diminuiu, ficando em 107,2\%. O Gráfico 1 traz um comparativo entre o desempenho do Brasil, Finlândia e Coreia do Sul com a média geral do desempenho dos países avaliados em cada período.

Gráfico 1 - Comparativo do desempenho no Pisa

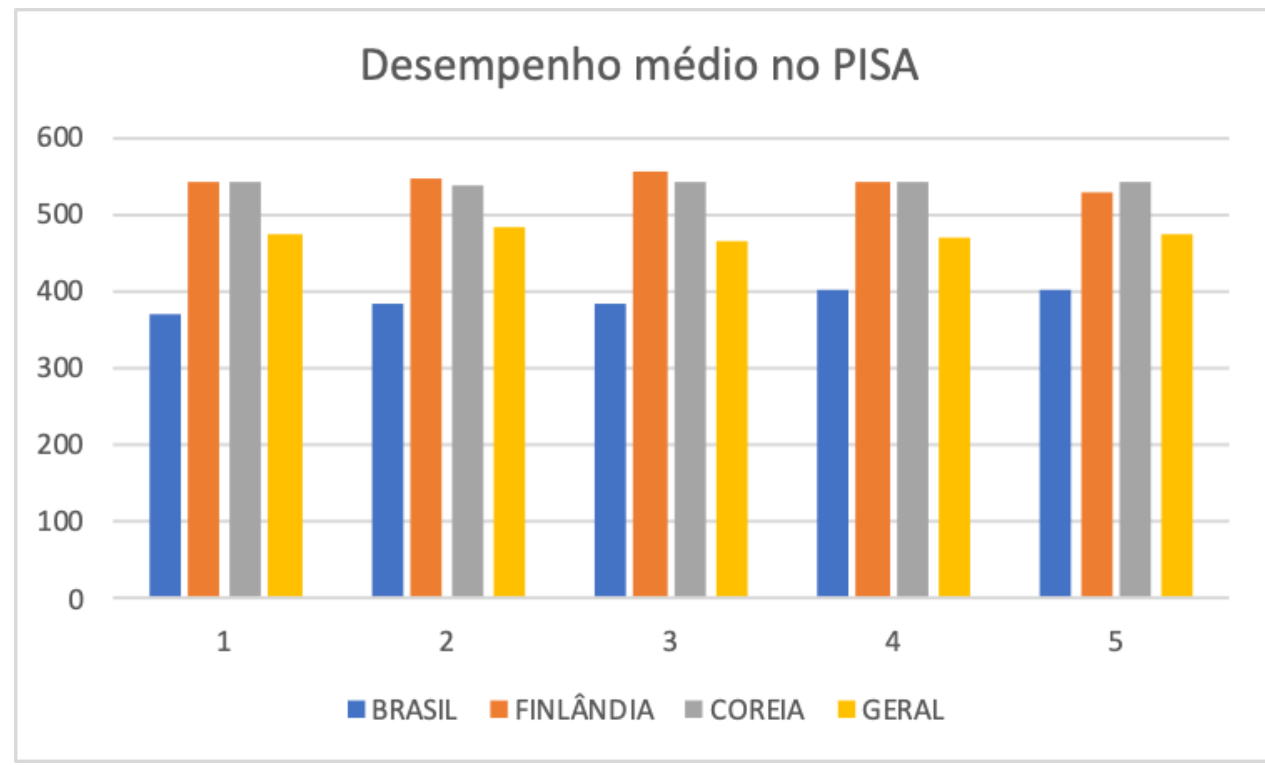

Fonte: elaborado pelo autor (2018) com base nos dados do PISA (OCDE, 2016).

Nesse cenário, se for considerado o resultado do Brasil em 2012 (84,45\%) sobre o resultado médio de todos os países participantes, e se forem diminuídos do ano de 2000 
(77,8\%), ter-se-ia um resultado de 6,65\%, o que representaria o que o país cresceu em relação à média mundial. Realizando-se um cálculo elementar, dividindo-se os 6,65 por 12 (anos), obter-se-ia um resultado de $0,554 \%$ ao ano. Então, para se atingir o mesmo resultado médio de todos os países $(100 \%)$, será preciso: $100-84,45=15,55$. Assim, se dividem os $15,55 / 0,554=28,069$, ou seja, a quantidade de anos para se atingir a média mundial dos países participantes do Pisa.

O Gráfico 2 traz outro modelo com o mesmo comparativo entre o desempenho do Brasil, da Finlândia e da Coreia do Sul, com a média geral do desempenho dos países avaliados em cada período. Aqui é possível perceber um tênue crescimento do Brasil.

Gráfico 2 - Comparativo do desempenho no Pisa

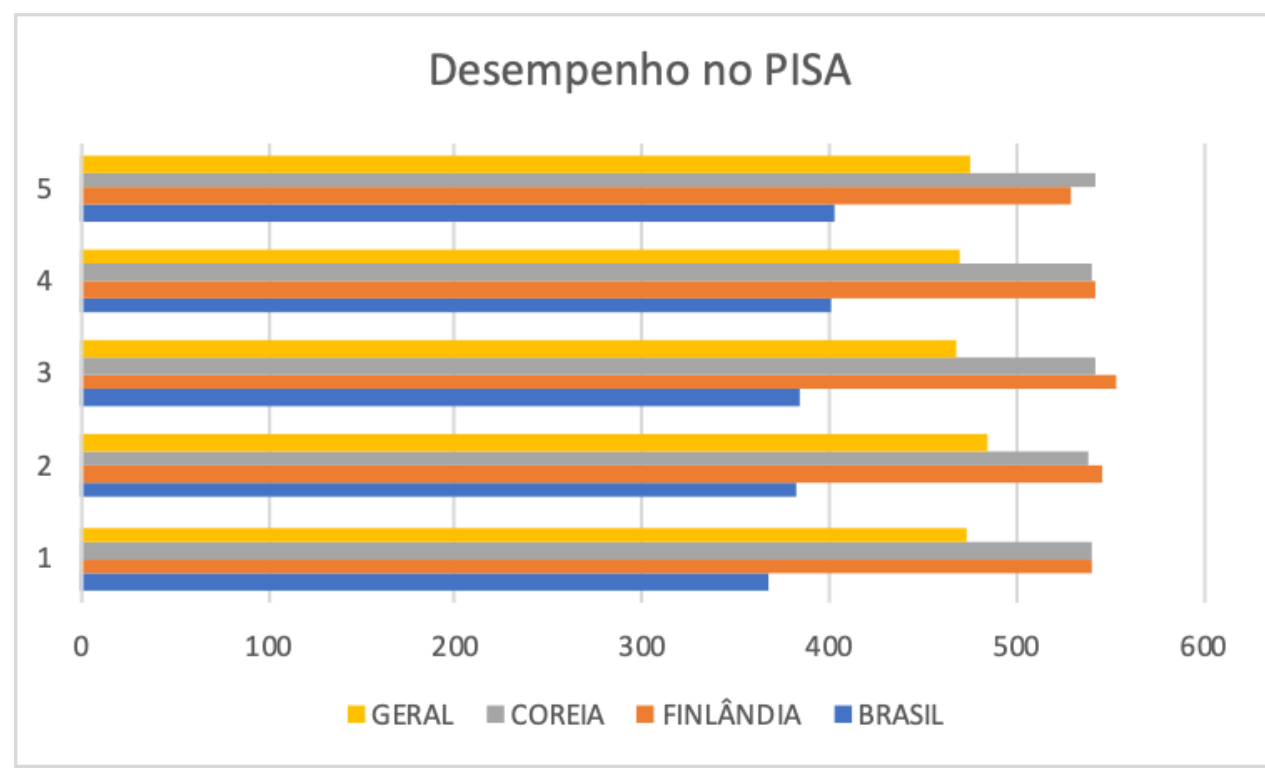

Fonte: elaborado pelo autor (2018) com base nos dados do PISA (OCDE, 2016).

Utilizando-se a mesma fórmula simplista para se fazer o comparativo e atingir o melhor resultado, seria preciso tomar os 68,37\% da performance do Brasil de 2012 e diminuir do obtido em 2000, que foi de 67,77\%, o que resultaria em 0,60. Dividindo-o por 12 anos, obter-se-ia um crescimento de $0,05 \%$ ao ano. Para se igualar ao melhor resultado $(100,00$ 68,37), seria preciso buscar os 31,63 resultantes dessa simplificação. Portanto, é preciso dividir os 31,63/0,05 =632,60, o que resultaria na quantidade de anos necessários para igualar o resultado do Brasil ao do país primeiro colocado.

Nesse viés, é preciso deixar claro que, primeiro, como dito, o cálculo é simplista, pois tem base nos cinco resultados do Pisa de 2000 a 2012. Tanto na projeção para se atingir a média mundial como no melhor resultado mundial, considerou-se uma projeção dos 
resultados passados (12 anos) para o futuro, ponderando-se que todos os países tivessem tido a mesma projeção relativa aos resultados anteriores, a exemplo do que se exercitou com os do Brasil. Dessa maneira, utilizou-se a fórmula mais básica e lógica para projetar o ponto presente (baseado em toda sua base histórica - 12 anos) para os pontos futuros desejados. É um flagrante da fotografia de todo o desempenho avaliado nesses 12 anos, lançado hipoteticamente para o futuro.

\section{Os países expoentes na educação sob perspectivas performativas}

Observa-se que os dois países expoentes na performance da Educação, apontados especialmente pelos exames do Pisa, são a Finlândia e a Coreia do Sul, que têm práticas totalmente diferenciadas, mas que chegam a um mesmo resultado de ponta.

Na Finlândia, o sucesso do seu sistema educacional parece ser em parte cultural, haja vista que os alunos estudam em um ambiente descontraído e informal. Segundo a OCDE, as crianças finlandesas gastam o menor número de horas em sala de aula em relação ao mundo desenvolvido (BURRIDGE, 2010). Em 2006, os alunos da Finlândia alcançaram os melhores resultados médios em Ciência e Leitura em todo o mundo desenvolvido. Em exames da OCDE para a faixa de 15 anos de idade, que integra o Pisa, eles ficaram em segundo lugar em Matemática, superados apenas por adolescentes da Coreia do Sul (BURRIDGE, 2010).

A estratégia usada em praticamente todas as lições é a colocação de um professor adicional que ajuda aqueles que têm dificuldade em um assunto particular. Os alunos são mantidos na mesma sala de aula, independentemente das diferenças em relação ao processo educativo. A ministra da Educação da Finlândia, Henna Virkkunen, orgulha-se do recorde de seu país, mas seu próximo objetivo é orientar os alunos mais brilhantes (BURRIDGE, 2010). Outro detalhe significativo na Finlândia é que a pobreza praticamente inexiste, fato que deixa todas as crianças niveladas, em termos de condições socioeconômicas, para enfrentar sua educação escolar.

Na Coreia do Sul, há diferenças impressionantes em comparação ao sistema de ensino da Finlândia. O maior exemplo é que, enquanto na Finlândia os alunos têm o menor número de horas em sala de aula, em comparação com o mundo desenvolvido, na Coreia do Sul, na verdade, eles estudam mais que as crianças de qualquer outro país no mundo. Outro exemplo é o intervalo, pois, na Finlândia, eles oferecem às crianças um número significativo de brincadeiras, e os alunos têm 75 minutos de recesso por dia. Não há recesso real na Coreia do Sul. A única pausa que as crianças coreanas têm é uma de 10 minutos para circularem entre as 
classes. Por outro lado, enquanto na Finlândia não há foco competitivo, em especial entre as escolas e os alunos, na Coreia do Sul isso é amplamente destacado e exerce forte pressão nas escolas e nos alunos.

Pode-se constatar a partir desses dois países - Finlândia e Coreia do Sul - com estratégias e políticas diferentes entre si, mas liderando os resultados na série histórica do PISA, que o mais importante é, efetivamente, a atenção e a preocupação constante com a Educação. Portanto, trata-se de escolhas, ou seja, decisões, que embora não sejam fáceis, são elementares, além de se tratar de um dos fundamentos mais preciosos da ciência administrativa e que irá resultar em uma qualidade socialmente referenciada, maior ou menor, considerando a intensidade que se empregar esse foco.

\section{Considerações finais}

Tornou-se consensual que se hoje não houver um investimento adequado em Educação, amanhã será necessário muito mais investimento para se construir presídios. Essa premissa destaca a importância do ato de educar, uma vez que, a Educação potencializa o sujeito e, o termo - potencializar pode estar relacionado à perspectiva de um ser humano mais consciente, cidadão. Tem-se, então, um hiato na Educação na medida em que ela não vai além dos interesses do mercado, deixando de lado aspectos relacionados â formação humana.

No Brasil, nos encontramos em trilhas nem sempre louváveis em relação aos processos políticos e de politização. Esta realidade é mais avançada nos países do norte. Nestes a impunidade é menos visível, e os processos de normatização colaboram para comportamentos éticos. Em nosso caso, de certa forma pode-se afirmar que existe cenários éticos desfavoráveis e a Educação não parece esboçar movimentos na direção de se obter uma correção desse quadro, uma vez que e mesma ao mesmo tempo que procura determinar sofre impactos da determinação dos cenários políticos, econômicos e sociais.

A Educação, numa perspectiva mais ampla, não contempla o desenvolvimento de competências para a emancipação do sujeito, entretanto, este é um horizonte a ser buscado pelos processos educacionais. Os projetos e ações nessa direção terão relevância para que a Educação possa de fato contemplar o mais próximo possível o desenvolvimento humano, ou seja, formar um ser humano na perspectiva do que foi referido de um estado consciente.

A partir dos cenários apresentados, a Educação, historicamente, não é objeto de uma atenção plena, e de sólidas políticas educacionais, no Brasil. Porém, há um universo de novas possibilidades, de novas ferramentas, de novas ciências e de novos processos a serem 
desenvolvidos e aplicados para o alcance para se obter avanços nos processos educacionais voltado e melhores patamares de vida, de maneira especial, em termos de Brasil.

As diferenças enormes existentes entre o ensino da Finlândia e o da Coreia do Sul, ambos com os melhores resultados em nível mundial, demonstra, de certa forma, respeitando às peculiaridades, que existe possível consistência em termos de políticas públicas educacionais. Possivelmente, de tudo o que aqui foi dito sobre os cenários educacionais na contemporaneidade e suas reflexões a respeito das diferenças e das performances, essa seja a maior e mais importante constatação a ser observada e refletida por todos que se preocupam com uma Educação melhor e com um país mais desenvolvido e com um nível de cidadania mais acentuado, visível e sentido por cada indivíduo. A partir do ajuste desse ponto, dar-se-ia ao início da caminhada para que a Educação possa dar uma contribuição mais positiva para a sociedade de educar o ser humano para um estado mais consciente.

A vida sempre poderá ser aprimorada e sempre a Educação terá um papel importante em um desenvolvimento efetivo, especialmente contemplando os aspectos de cidadania e de libertação do ser, via aperfeiçoamentos, muito em particular, através dos processos formativos. Como é possível deduzir, a partir do cenário da contemporaneidade, hoje há um significativo hiato para com esses cuidados, por parte da Educação, atingindo grandes contingentes populacionais em nosso planeta. Existe lacuna entre o que é proporcionado às coletividades e a perspectiva de um ser humano emancipado das amarras sociais, políticas e econômicas, ou seja, um ser humano em um estado mais consciente.

\section{REFERÊNCIAS}

ABBAGNANO, Nicola. Dicionário de Filosofia. 5. ed. São Paulo: M. Fontes, 2007.

BRASIL. Ministério da Educação. Escola de gestores da Educação Básica. Declaração dos Direitos Humanos (1948). Brasília: Ministério da Educação, Biblioteca do curso da Escola de Gestores da Educação Básica, 2004. Disponível em:

http://escoladegestores.mec.gov.br/site/8-biblioteca/pdf/declaracao_dh_site-onu.pdf. Acesso em: 2 jul. 2016.

BUNGE, Mario. Dicionário de filosofia. São Paulo: Perspectivas, 2002.

BURRIDGE, Tom. Why do Finland's schools get the best results? BBC, World News America, 7 abr. 2010. Disponível em: http://news.bbc.co.uk/2/hi/8601207.stm. Acesso em: 14 jul. 2018. 
HERRÁN GASCÓN, Agustín de la. Enfoque radical e inclusivo de la formación. Revista Iberoamericana sobre Calidad, Eficacia y Cambio en Educación, Barcelona, v. 12, 2, p. 163-264. RINACE, 2014.

HERRÁN GASCÓN, Agustín de la; CORTINA SELVA, Mar. La muerte y su Didáctica. Manual para Educación Infantil, Primaria y Secundaria 2. ed. Madrid: Universitas, 2006.

IDEB. Como é calculado. Portal QEdu Academia, c2018. Disponível em:

http://academia.qedu.org.br/ideb/como-o-ideb-e-calculado/. Acesso em: 14 jul. 2018.

OCDE - Organização para a Cooperação e Desenvolvimento Econômico. Brasil no PISA 2015: análises e reflexões sobre o desempenho dos estudantes brasileiros. São Paulo:

Fundação Santillana, 2016. Disponível em:

http://download.inep.gov.br/acoes_internacionais/pisa/resultados/2015/pisa2015_completo_fi nal_baixa.pdf. Acesso em: 15 jul. 2018.

SABBI, Carlos Roberto. Pedagogia radical e inclusiva: nas trilhas de elementos educativos para uma cidadania mais consciente. Projeto de tese (Doutorado em Educação). Universidade de Caxias do Sul, Caxias do Sul, em cotutela com Universidad Autónoma de Madrid, 2018.

TREVISAN, Amarildo; DEVECHI, Catia Piccolo Viero. Abordagens na formação de professores: uma reconstrução aproximativa do campo conceitual. Rev. Bras. Educ. v. 16, n. 47, p. 409-426, 2011,

United Nations Human Rights. Universal Declaration of Human Rights (1948). Office of the United Nations High Commissioner for Human Rights, 24 nov. 2015. Disponível em: http://www.ohchr.org/EN/UDHR/Documents/UDHR_Translations/eng.pdf. Acesso em: 14 jul. 2018.

\section{Como referenciar este artigo}

SABBI, Carlos Roberto; ROSA, Geraldo Antônio da; HERRÁN GASCÓN, Agustín de la. Cenários educacionais na contemporaneidade: reflexões a respeito das diferenças e das performances. Revista Ibero-Americana de Estudos em Educação, Araraquara, v. 15, n. 2, p. 682-696, abr./jun. 2020. e-ISSN: 1982-5587. DOI: https://doi.org/10.21723/riaee.v15i2.12366

Submetido em: 19/03/2019

Revisões requeridas: 24/10/2019

Aprovado em: 15/12/2019

Publicado em: 20/02/2020 